\title{
Mo/Mo silicide composites prepared by pressure-assisted reactive infiltration
}

\author{
K. Iždinský ${ }^{1 *}$, L. Senčeková ${ }^{1}$, F. Simančík ${ }^{1}$, N. Beronská ${ }^{1}$, P. Švec ${ }^{2}$ \\ ${ }^{1}$ Institute of Materials and Machine Mechanics, Slovak Academy of Sciences, \\ Račianska 75, 83102 Bratislava, Slovak Republic \\ ${ }^{2}$ Institute of Technologies and Materials, Faculty of Mechanical Engineering, Slovak University of Technology in \\ Bratislava, Pionierska 15, 83103 Bratislava, Slovak Republic
}

Received 16 July 2015, received in revised form 24 September 2015, accepted 25 September 2015

\begin{abstract}
Pressure-assisted reactive infiltration of Mo wire preforms with molten silicon was tested in order to prepare compact and void-free $\mathrm{Mo} / \mathrm{Mo}$ silicide composite. It appears that when Mo silicides were formed in a stressed condition, the porosity and extensive cracking could be suppressed. Relatively compact samples were prepared. The cumulative failure mode was recorded during bending tests, and the excellent oxidation resistance had been confirmed by TG measurements.
\end{abstract}

K e y w o r d s: Mo silicides, pressure-assisted reactive infiltration, structural analysis

\section{Introduction}

The further development of many technical fields is strongly restricted by the limits of current structural and protection materials. This is especially true for high-tech applications working in extreme conditions and environments such as aircraft and automobile engines, space vehicles, high-temperature or high-pressure fusion, chemical reactors, etc. Their reliable and efficient performance requires revolutionary improved materials able to withstand complex loading usually combining several factors like high temperature, high heat flux, corrosion (oxidation) attack and multi-axial dynamically changing forces. This all would be accomplished using manufacturing techniques desirably enabling the cost-efficient production of net shape (also very complex) structural parts $[1$, 2].

Refractory metals including Mo exhibit high-temperature strength and ductility, they are readily formed to shape, have high thermal shock resistance and high fracture toughness. However, they undergo active oxidation in these applications and are limited by creep resistance at elevated temperatures.

Refractory metal (Mo, Nb) silicides can create stable and renewing oxide at a surface and thus protect the material from further corrosion. Their main problem is high ductile - brittle transition temperature $($ DBTT $) \sim 1100 \mathrm{~K}$, limited creep resistance above $1500 \mathrm{~K}$, low oxidation resistance at moderate temperatures (pesting behaviour) and in sulphuric environments. Manufacturing of complex parts is also difficult.

Actually, the properties of refractory metals and their silicides are complementary, and when put together they have the potential to eliminate the drawbacks of the counterpart. The actual challenge here is to find a way that would preferentially employ the desired strengths and not weaknesses of both in the overall performance of the high-temperature structural material.

Reactive infiltration might be a quite promising technology to meet these demands. However, it is accompanied by some drawbacks that limit its potential at a current stage.

As already reported [3, 4], when a Mo wire is dipped into excessively molten $\mathrm{Si}$, rapid dissolution takes place. This reaction, exothermic in nature, is so rapid and intense that it cannot be effectively controlled. The very convenient way how to govern the

*Corresponding author: tel. +421 2 49268226; fax: +421 2 49268312; e-mail address: ummsizd@savba.sk 

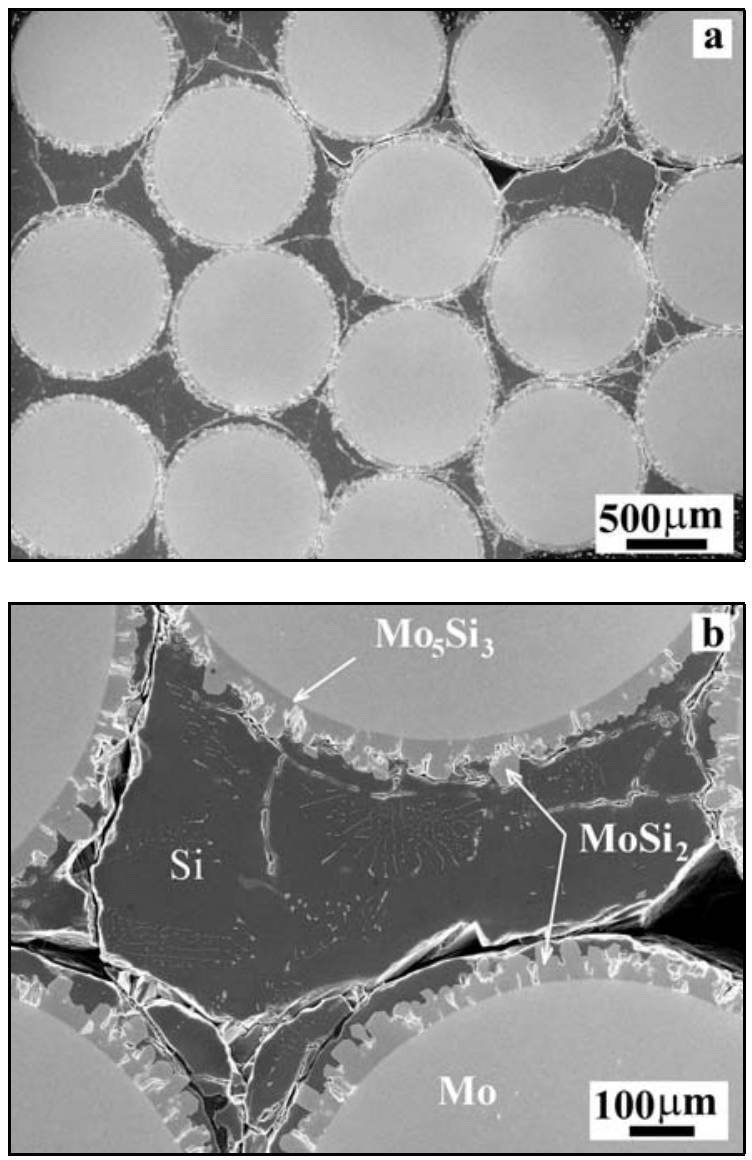

Fig. 1. SE micrographs revealing structure of as-infiltrated Mo/Mo silicide wire composite (a), inter-wire location with unreacted silicon and preliminarily formed silicides (b).

dissolution and silicide forming reaction is to limit the amount of Si that comes into contact with Mo. Then only a part of Mo participates in the reaction that stops as soon as $\mathrm{Si}$ is consumed.

When a wire preform is infiltrated with $\mathrm{Si}, \mathrm{MoSi}_{2}$ and a thin continuous layer of $\mathrm{Mo}_{5} \mathrm{Si}_{3}$, silicides are formed on the surface of Mo wires. Inter-wire locations are filled with the rest of $\mathrm{Si}$ interconnecting the Mo/Mo silicide wires. A typical example is presented in secondary electron (SE) micrograph in Fig. 1. The unreacted silicon has to be restrained in order to stabilize the composite structure for high-temperature applications.

It appears that post-infiltration annealing at $1600^{\circ} \mathrm{C} / 30 \mathrm{~min}$ is sufficient to transform the rest of $\mathrm{Si}$ into silicides. However, all these reactions are accompanied by volume changes that result in residual porosity or even in the disintegration of the preform.

Therefore hot pressing at $1800^{\circ} \mathrm{C} / 60 \mathrm{~min} / 30 \mathrm{MPa}$ in vacuum $30 \mathrm{~Pa}$ was adapted to compact the composite structure and to restrain the residual porosity. It appears that even this operation was not sufficient to restrain the pores, particularly in inter-wire locations.
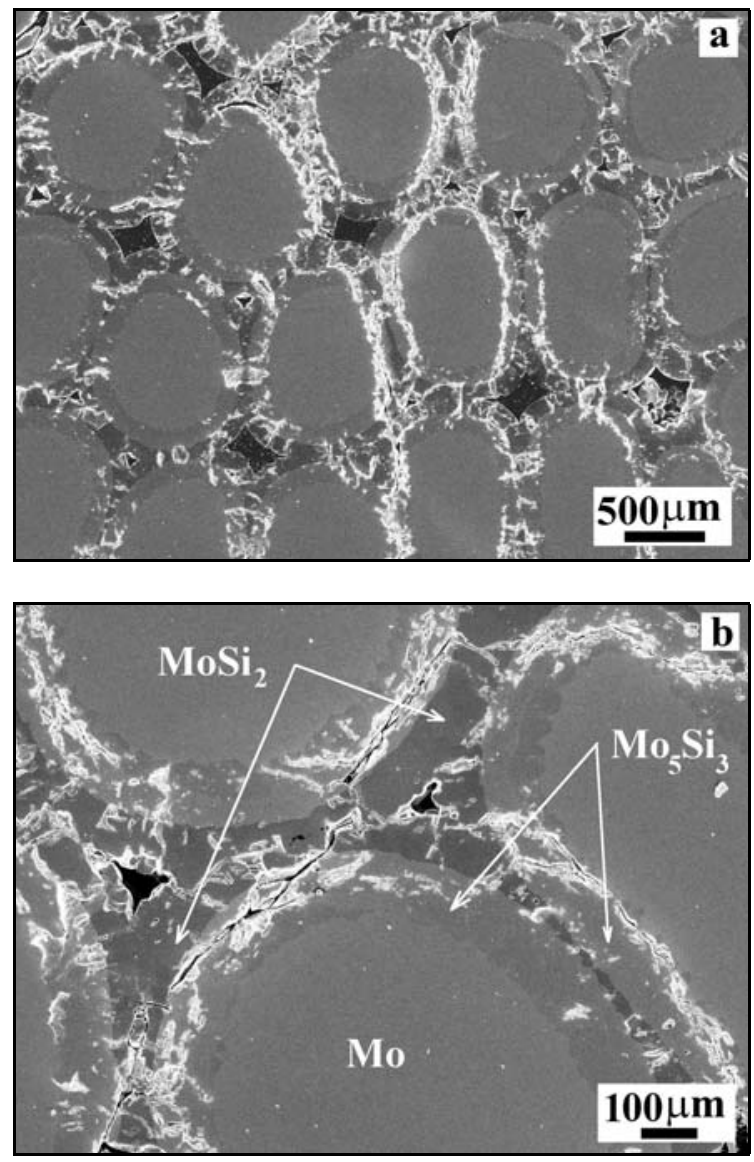

Fig. 2. SE micrographs revealing structure of infiltrated Mo/Mo silicide wire composite additionally hot pressed at $1800^{\circ} \mathrm{C} / 60 \mathrm{~min} / 30 \mathrm{MPa}$ (a), inter-wire location with $\mathrm{Mo}_{5} \mathrm{Si}_{3}$ and $\mathrm{MoSi}_{2}$ silicides (b).

Mo wires were deformed to some extent, but it was not enough to close the pores.

These preliminary results were not satisfactory, and modified approaches directed towards the obtaining of silicon and void-free composite structures were examined. This work reports the results achieved by applying pressure-assisted reactive infiltration.

\section{Experimental material}

Mo/Mo silicide composites were prepared by pressure-assisted reactive infiltration of Mo wire preforms with silicon. Mo wires with the diameter of $1 \pm 0.015 \mathrm{~mm}$ and $99.97 \%$ purity (annealed, medium hard, purchased from Plansee Reute) were cut and densely packed into a rectangular graphite tool whereas the inter-wire locations were filled with fine Si powder (monocrystalline Si with high purity $99.99999 \%$ ). This arrangement had been subjected to heating in Ar atmosphere. At the temperature of $1390^{\circ} \mathrm{C}$, the external pressure of $30 \mathrm{MPa}$ was applied. 

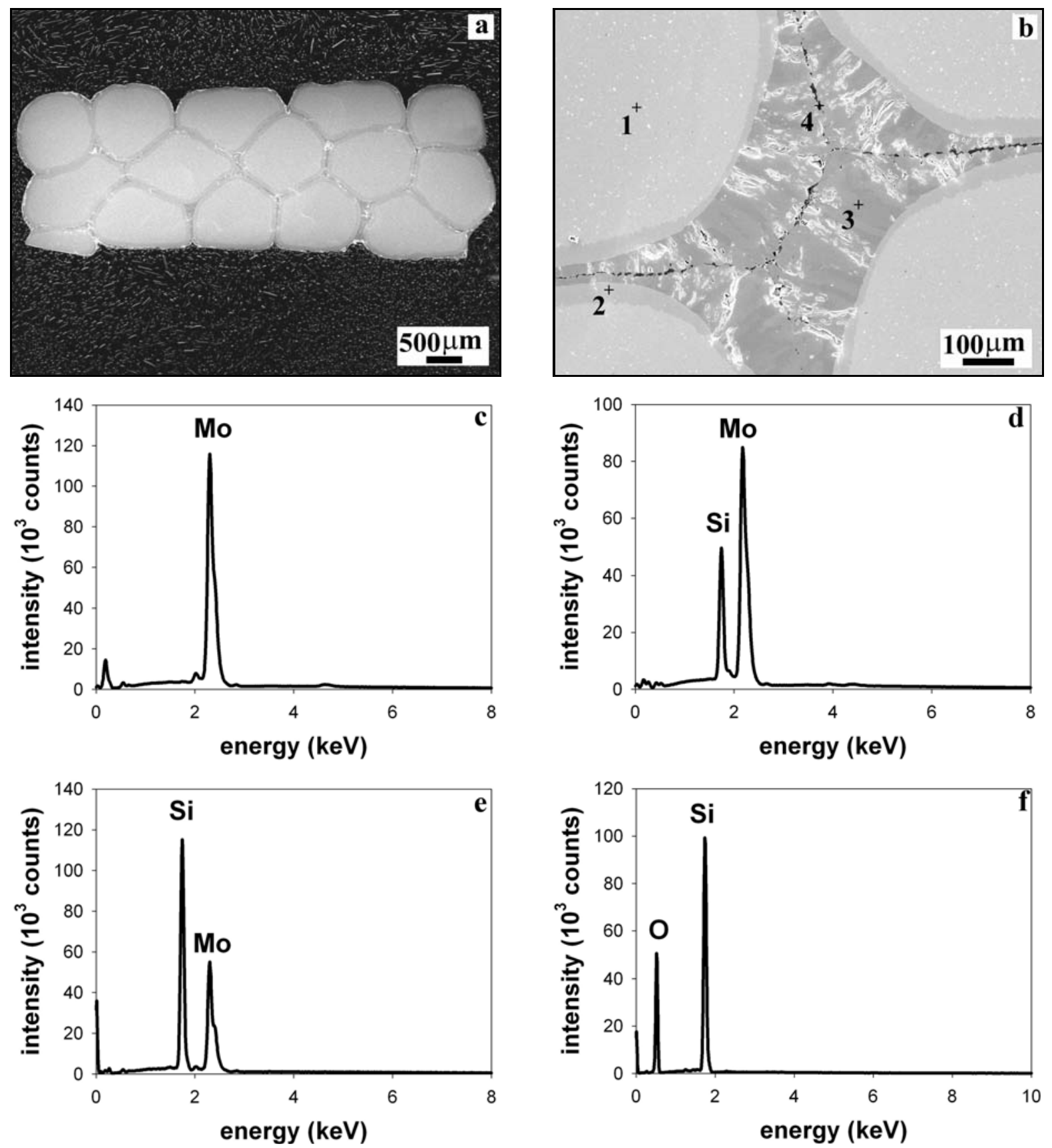

Fig. 3. SE micrographs revealing structure of infiltrated Mo/Mo silicide composite prepared by pressure-assisted reactive infiltration (a), inter-wire location with Mo silicides and points of EDX analysis (b), EDX point spectrum corresponding to $\mathrm{Mo}$ in 1 (c), $\mathrm{Mo}_{5} \mathrm{Si}_{3}$ in 2 (d), $\mathrm{MoSi}_{2}$ in 3 (e) and $\mathrm{SiO}_{2}$ in 4 (f).

The simultaneous heating and pressing continued up to the temperature of $1500^{\circ} \mathrm{C}$ and was followed by isothermal exposure for $30 \mathrm{~min}$ at $1500^{\circ} \mathrm{C} / 30 \mathrm{MPa}$.

Composite samples were cut and prepared for structural observations by a standard metallographic procedure. Electron microscopy observations were performed using a field emission scanning electron microscope JEOL 7600F. Structural studies were performed using secondary electron (SE) microscopy observations. Energy-dispersive spectroscopy (EDS) was employed for chemical analysis using Oxford EDX system (INCA Energy).

As-infiltrated samples were subjected to room temperature bending tests to check the failure mode of the Mo/Mo silicide composites. Three-point bending with the span length of $20 \mathrm{~mm}$ and the constant crosshead speed of $0.017 \mathrm{~mm} \mathrm{~s}^{-1}$ had been applied using Zwick universal testing machine.

The property characterization had been completed by comparative tests where oxidation of Mo pre- 


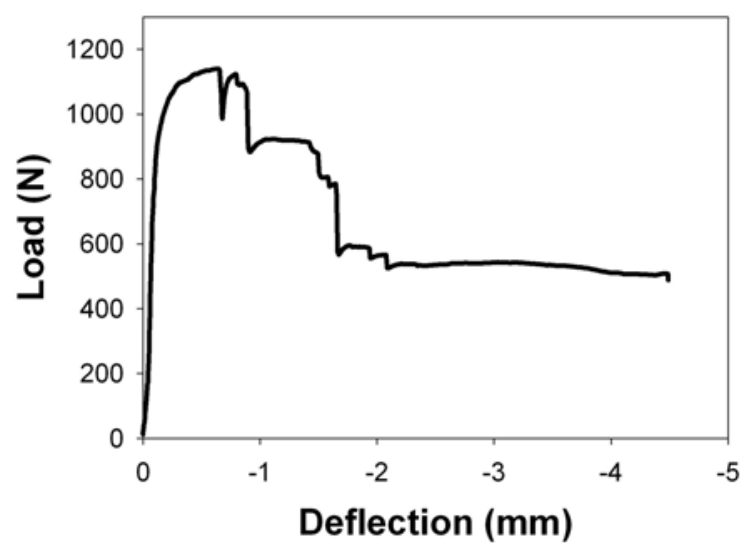

Fig. 4. Typical load vs. deflection record for Mo/Mo silicide composite prepared by pressure-assisted reactive infiltration.

form and Mo/Mo silicide composite sample were determined by thermogravimetric analysis (TGA) using LINSEIS L81II-1550 thermal analyzer. Samples were heated in the air up to the temperature of $1200^{\circ} \mathrm{C}$ at a heating rate of $10^{\circ} \mathrm{C} \mathrm{min}-1$ and the corresponding relative weight changes were recorded and compared.

\section{Results}

Relatively compact composite samples had been prepared by pressure-assisted reactive infiltration as presented in Fig. 3. The Mo wires underwent intense plastic deformation and came into close contact even in problematic locations where 3 or 4 wires meet. The large pores are actually not observed. The $\mathrm{Mo}_{5} \mathrm{Si}_{3}$ layer is quite thin as can be seen in Fig. 3b. Dark dots decorating the interface are mostly $\mathrm{SiO}_{2}$ as confirmed by EDS analysis.

The cardinal question here is whether the Mo/Mo silicide composite prepared in this way has the potential to provide the desired toughness and corresponding protection against oxidation.

The typical load vs. deflection curve for the Mo/Mo silicide composite subjected to three-point bending test is presented in Fig. 4. The samples were tested in the as-received condition, so the results need to be taken into account rather qualitatively. However, if we use the rectangular approximation of the cross-section in Fig. 3a, then the maximal flexural stress in the record would correspond to $1400 \mathrm{MPa}$.

The most important finding from a qualitative point of view is the cumulative failure mode, which is quite obvious. It indicates that the propagation of initial cracks was effectively stopped by Mo wires, and sudden overall destruction of the sample did not take place.

Metallographic observation of bent samples con-
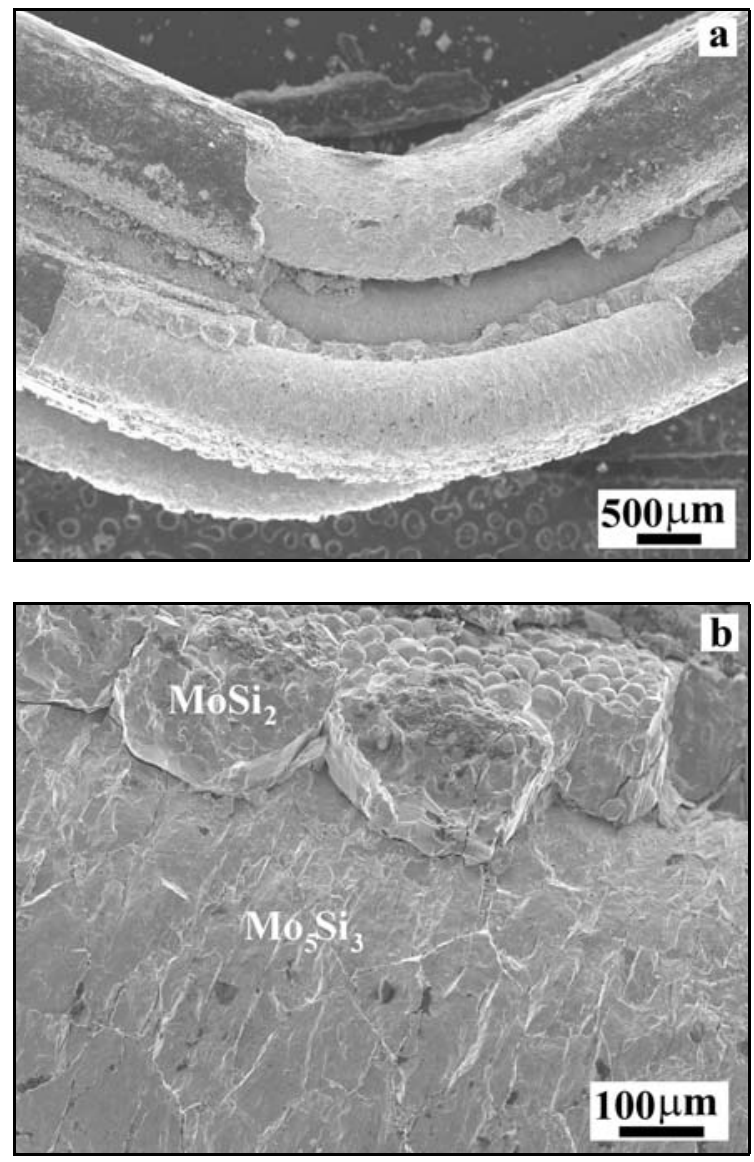

Fig. 5. SE micrographs revealing the cumulative failure mode of Mo/Mo silicide composite sample (a) and different fracture behaviour of $\mathrm{Mo}_{5} \mathrm{Si}_{3}$ and $\mathrm{MoSi}_{2}$ silicides (b).

firmed the toughness of the composite as presented in Fig. 5. The Mo wires were plastically deformed, and the surface silicides broke in a brittle mode. EDS analysis further revealed very good adherence of $\mathrm{Mo}_{5} \mathrm{Si}_{3}$ to the Mo wire, whereas $\mathrm{MoSi}_{2}$ exhibited no plasticity and its fragments fell off.

Finally, the comparative oxidation resistance test for infiltrated and non-infiltrated Mo preform was accomplished. In order to reveal the condition of the Mo/Mo silicide composite just before the TGA test, structural observations had been performed. It appears that as shown in Fig. 6, the Mo wire surfaces were covered by a thin layer of $\mathrm{MoSi}_{2}$ silicide.

The mass changes of both samples subjected to heating in the atmosphere are compared in Fig. 7 . The mass of Mo preform increases above the temperature of $600^{\circ} \mathrm{C}$ up to approximately $1000^{\circ} \mathrm{C}$ rapidly. Then the mass decrease dominates up to the end of the heating cycle $\left(1200^{\circ} \mathrm{C}\right)$.

On the contrary, only very little mass change had been recorded for the Mo/Mo silicide composite sample. A slight increase (approx. $0.4 \%$ ) had been observed in the temperature interval $383.8-718.9^{\circ} \mathrm{C}$. 


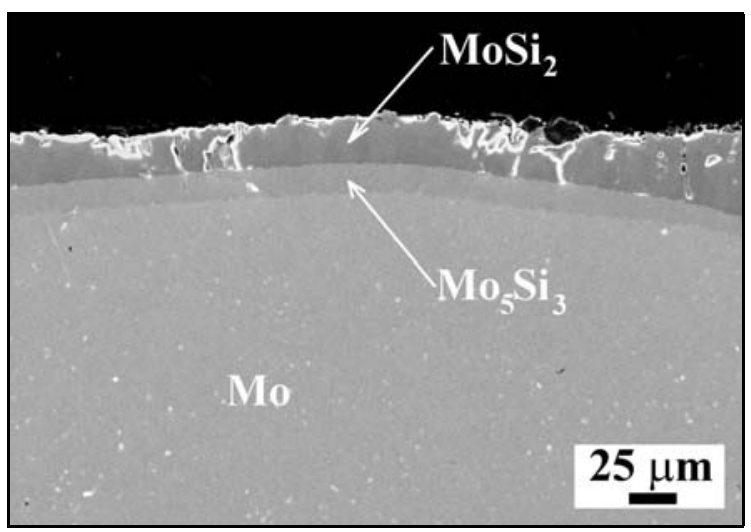

Fig. 6. SE micrograph revealing the cross-section of Mo/Mo silicide composite sample subjected to TG measurement.
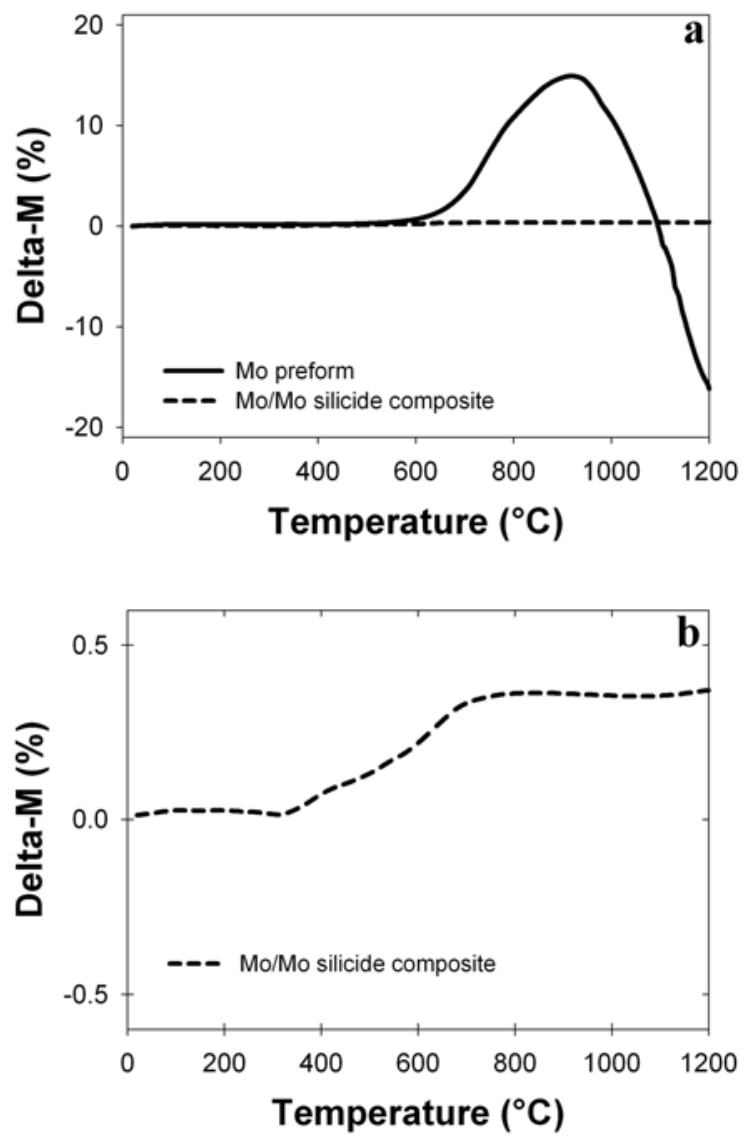

Fig. 7. Mass change dependence on temperature during heating of Mo preform and Mo/Mo silicide composite sample in air (a), Mo/Mo silicide composite record in the larger resolution (b).

\section{Discussion of results}

Currently available high-temperature structural materials such as e.g. Ni-based superalloys are lim- ited to use at temperatures about $1100^{\circ} \mathrm{C}$. More advanced NiAl-based aluminide alloys have the potential for use at temperatures up to $1200^{\circ} \mathrm{C}$. However, many critical high-temperature applications require temperature capabilities that exceed this temperature by at least $200^{\circ} \mathrm{C}$. The melting temperature $\left(T_{\mathrm{m}}\right)$ of a material for structural applications at $1400^{\circ} \mathrm{C}$ should be $>2000^{\circ} \mathrm{C}$ so that, at most, $0.75 T_{\mathrm{m}}$ is reached during service, and appreciable high-temperature strength is maintained [5]. Of the potential candidate systems, Mo silicides are particularly attractive due to their high melting points $\left(\mathrm{Mo}_{3} \mathrm{Si}-2025^{\circ} \mathrm{C} ; \mathrm{Mo}_{5} \mathrm{Si}_{3}-\right.$ $2180^{\circ} \mathrm{C} ; \mathrm{MoSi}_{2}-2020^{\circ} \mathrm{C}$ ).

The properties of metallic Mo and Mo silicides go together well, and the proper way how to employ them to gain the desired synergy might be the concept of functionally graded materials (FGM).

In the previous approach, continuous Mo wire preform was infiltrated with molten silicon and the partial reactions between melt and Mo wire took place forming silicides predominantly in the vicinity of the wire surface. Some unreacted silicon remained in the inter-wire locations, thus making in situ FGM with increasing metal content towards the core of the wire. The drawback of this approach is the necessity to finalize the silicide forming reaction and the reduction of residual porosity. This is not a trivial task as the newly formed silicides are very strong and difficult to deform. As reported even hot pressing at $1800{ }^{\circ} \mathrm{C} / 60$ $\min / 30 \mathrm{MPa}$ is not enough to perform the required compaction $[3,4]$.

Various other approaches had been examined in order to perform the desired compaction. $\mathrm{Nb}$ in the form of wire or foil was attempted as a bonding agent in [3]. Secondary infiltration with Ni followed by HIP [6], as well as compaction via $\mathrm{Ni}$ interlayers [7] was experienced too. These attempts were successful in terms of compaction; however, the introduction of the third element led to the formation of new phases $\left(\mathrm{Nb}, \mathrm{Nb}_{5} \mathrm{Si}_{3}\right.$, $\mathrm{MoNiSi}, \mathrm{Ni}_{2} \mathrm{Si}$ ) with no clear effect on the composite performance. Therefore, the approach remaining within the binary Mo-Si is clearly preferable and desired.

In the present approach based on pressure-assisted reactive infiltration, the composite was prepared in one operation simultaneously bringing together both infiltration and hot pressing. Mo wires were pressed, and $\mathrm{Si}$ powder in the inter-wire locations had been melted in the stressed condition as well. Obviously, there were only narrow gaps between the plastically deformed Mo wires, and these were filled with newly formed silicides. As the amount of silicon was properly adjusted, the newly formed silicides could fill nearly all the empty spaces eliminating thus the formation of excessive porosity.

The great ambition of the FGM concept is to contribute with ductility and oxidation resistance to the 
overall performance of the Mo/Mo silicide composite. Three-point bending tests confirmed one part of these expectations as the composite samples exhibited the cumulative failure mode. After the breakage of silicides $\left(\mathrm{MoSi}_{2}\right)$, the wires overtook the loading, and the catastrophic fracture did not take place. The samples were seriously deformed (bent) but not broken. It is crucial to know that the preparation procedure does not change the metallic framework into a fragile body. Therefore, the load bearing capacity of the composite is quite promising.

TGA curves for Mo preform and Mo/Mo silicide composite are completely different. The oxidation of molybdenum from room temperature to $1700^{\circ} \mathrm{C}$ involves some different oxidation processes [8]. Below $600^{\circ} \mathrm{C}$ a compact oxide film is formed which acts to prevent further reaction. The oxide film begins to volatilize at $600{ }^{\circ} \mathrm{C}$. At $795^{\circ} \mathrm{C}$ the oxide melts. Above $800^{\circ} \mathrm{C}$ oxidation occurs without appreciable oxide film formation. The volatile oxides consist of polymers of $\mathrm{MoO}_{3}$. This is confirmed in Fig. 7. In the beginning, the oxidation results into increasing mass, later on as the volatilization dominates the mass decreases quite rapidly.

Mass changes for Mo/Mo silicide composite are moderate when compared with Mo. As can be seen only very slight mass increase is recorded between 383.8 and $718.9^{\circ} \mathrm{C}$. This can be related to "pest oxidation" of $\mathrm{MoSi}_{2}$ that was first discovered by Fitzer in 1955 [9]. $\mathrm{MoSi}_{2}$ is known for its excellent oxidation resistance at high temperatures via the formation of a thin protective silica layer. However, $\mathrm{MoSi}_{2}$ suffers from accelerated oxidation at low temperatures around $500^{\circ} \mathrm{C}[10]$. This is believed to be associated with the absence of protective oxide scale at low temperatures due to the formation of volatile $\mathrm{MoO}_{3}$ [11]. Besides oxidation temperature $[12,13]$ and atmosphere [14], defects such as pores and cracks are recognized as factors greatly accelerating oxidation [15]. However, the protective effect of $\mathrm{MoSi}_{2}$ in the current composite when compared with Mo is quite obvious and undoubtedly confirms its potential for hightemperature applications.

The pressure-assisted reactive infiltration of Mo preform with molten $\mathrm{Si}$ does generally not lead to stable equilibrium phases. When subjected to high temperature the transformation goes on converting the initial higher $\left(\mathrm{MoSi}_{2}\right)$ into lower $\left(\mathrm{Mo}_{5} \mathrm{Si}_{3} ; \mathrm{Mo}_{3} \mathrm{Si}\right)$ silicides. This is always accompanied by volume changes and formation of porosity. However, even if not thermodynamically stable, the composite may exhibit some thermokinetic stability. Depending on particular temperature, the transformation can be slow enough to be acceptable by the final product itself. A typical example might be re-entry space vehicles where both mechanical and oxidation protection is required. However, the overall high-temperature exposure is in these applications limited to few hours. The current composite can be certainly adapted to survive these and similar conditions.

\section{Conclusions}

Preparation of Mo/Mo silicide composites via pressure-assisted reactive infiltration of Mo wire perform was assessed in this work. It appears that relatively compact samples without extensive pores and cracking can be prepared in this way where infiltration and hot pressing act simultaneously.

$\mathrm{Mo} / \mathrm{Mo}$ silicide composite samples subjected to three-point bending tests at room temperature exhibited cumulative failure modes where $\mathrm{MoSi}_{2}$ silicide fractured in a brittle manner. However, Mo wires experienced only plastic deformation and stopped the propagating cracks.

TGA measurements revealed just moderate oxidation of Mo/Mo silicide composite and confirmed its potential for high-temperature applications.

The preparation route of Mo/Mo silicide composites does not generally provide stable equilibrium silicide phases. However, they can be useful in applications where the Mo-Si diffusion with respect to the required temperature and time of exposure is still relatively slow. The temperature interval above that of Ni-based intermetallics is quite realistic.

\section{Acknowledgements}

This work was accomplished within the 7th Framework Program Project Micro and Nanocrystalline Silicide - Refractory Metals FGM for Materials Innovation in Transport Applications (Project acronym SILTRANS); grant agreement No. 229127. This work was co-funded by the Slovak Research and Development Agency under the contract No. DO7RP-0023-09. Financial support from the SRDA APVV-0556-12 project is gratefully acknowledged.

\section{References}

[1] Bewlay, B. P., Jackson, M. R., Zhao, J. C., Subramanian, P. R.: Metall. Mater. Trans. A, 34, 2003, p. 2043. doi:10.1007/s11661-003-0269-8

[2] Schneibel, J. H.: Beyond Nickel-Base Superalloys. Oak Ridge, Oak Ridge National Laboratory 2001.

[3] Senčeková, L., Iždinský, K., Simančík, F., Minár, P., Nosko, M., Švec, P.: Kovove Mater., 50, 2012, p. 425.

[4] Senčeková, L.: Mo/Mo-Silicide Composites Prepared by Liquid Silicon Infiltration. [Ph.D. Thesis]. Bratislava, IMMM SAS 2012.

[5] Natesan, K., Deevi, S. C.: Intermetallics, 8, 2000, p. 1147. doi:10.1016/S0966-9795(00)00060-1

[6] Iždinský, K., Senčeková, L., Simančík, F., Nosko, M., Schoberth, A.: Kovove Mater., 51, 2013, p. 327. 
[7] Senčeková, L., Iždinský, K., Simančík, F., Stefánik, P., Švec, P.: In: Proceedings of 15th International Conference on Metallography 2013. Eds.: Longauerová, M., Zubko, P. Košice, Institute of Materials Research of SAS 2013, p. 77.

[8] Gulbransen, E. A., Andrew, K. F., Brassart, F. A.: J. Electrochem. Soc., 110, 1963, p. 952. doi:10.1149/1.2425918

[9] Fitzer, E.: In: Warmfeste und Korrosionsbestandige Sinterwerkstoffe. 2nd Plansee Seminar. Ed.: Benesovsky, F. Elmsford, Pergamon Press 1956.

[10] Liu, Y. Q., Shao, G., Tsakiropoulos, P.: Intermetallics, 9, 2001, p. 125. doi:10.1016/S0966-9795(00)00114-X
[11] Zhang, F., Zhang, L., Shan, A., Wu, J.: Intermetallics, 14, 2006, p. 406. doi:10.1016/j.intermet.2005.08.001

[12] Berztiss, D. A., Cerchiara, R. R., Gulbransen, E. A., Pettit, F. S., Meier, G. H.: Mater Sci Eng A, 155, 1992, p. 165. doi:10.1016/0921-5093(92)90324-T

[13] Mescher, P. J.: Met Trans, 23A, 1992, p. 1763.

[14] Kurokawa, K., Ube, M., Takahashi, H., Takahashi, H.: J. Phys. IV, 10, 2000, p. 3. doi:10.1051/jp4:2000601

[15] Kuchino, J., Kurokawa, K., Shibayama, T., Takahashi, H.: Vacuum, 73, 2004, p. 623. doi:10.1016/j.vacuum.2003.12.081 